\title{
Deep Brain Stimulation Can Preserve Working Status in Parkinson's Disease
}

\author{
Gabriella Deli, ${ }^{1}$ István Balás, ${ }^{2}$ Tamás Dóczi, ${ }^{2,3}$ József Janszky, ${ }^{1,3}$ Kázmér Karádi, ${ }^{1}$ \\ Zsuzsanna Aschermann, ${ }^{1}$ Ferenc Nagy, ${ }^{1,4}$ Attila Makkos, ${ }^{1}$ Márton Kovács, ${ }^{1}$ Edit Bosnyák, ${ }^{1}$ \\ Norbert Kovács, ${ }^{1,3}$ and Sámuel Komoly ${ }^{1}$ \\ ${ }^{1}$ Department of Neurology, University of Pécs, Rét Utca 2, Pécs 7623, Hungary \\ ${ }^{2}$ Department of Neurosurgery, University of Pécs, Rét Utca 2, Pécs 7623, Hungary \\ ${ }^{3}$ MTA-PTE Clinical Neuroscience MR Research Group, Rét Utca 2, Pécs 7623, Hungary \\ ${ }^{4}$ Department of Neurology, Kaposi Mór County Hospital, Tallián Gyula Utca 16, Kaposvár 7400, Hungary
}

Correspondence should be addressed to Norbert Kovács; kovacsnorbert06@gmail.com

Received 30 April 2015; Revised 8 July 2015; Accepted 16 July 2015

Academic Editor: Eng-King Tan

Copyright (C) 2015 Gabriella Deli et al. This is an open access article distributed under the Creative Commons Attribution License, which permits unrestricted use, distribution, and reproduction in any medium, provided the original work is properly cited.

Objectives. Our investigation aimed at evaluating if bilateral subthalamic deep brain stimulation (DBS) could preserve working capability in Parkinson's disease (PD). Materials. We reviewed the data of 40 young ( $<60$ year-old) PD patients who underwent DBS implantation and had at least 2 years of follow-up. Patients were categorized based on their working capability at time of surgery: "active job" group $(n=20)$ and "no job" group $(n=20)$. Baseline characteristics were comparable. Quality of life (EQ-5D) and presence of active job were evaluated preoperatively and 2 years postoperatively. Results. Although similar (approximately 50\%) improvement was achieved in the severity of motor and major nonmotor symptoms in both groups, the postoperative quality of life was significantly better in the "active job" group ( 0.687 versus 0.587 , medians, $p<0.05)$. Majority ( $80 \%)$ of "active job" group members were able to preserve their job 2 years after the operation. However, only a minimal portion (5\%) of the "no job" group members was able to return to the world of active employees $(p<0.01)$. Conclusions. Although our study has several limitations, our results suggest that in patients with active job the appropriately "early" usage of DBS might help preserve working capability and gain higher improvement in quality of life.

The present scientific contribution is also dedicated to the 650th anniversary of the foundation of the University of Pécs, Hungary

\section{Introduction}

The 27-year-old deep brain stimulation (DBS) revolutionized the treatment of movement disorders including drugresistant tremor, advanced Parkinson's disease (PD) [1, 2], and dystonia [3]. Based on its high efficacy and relatively small side effect profile, more than 100,000 patients have undergone DBS implantation worldwide [4]. Approximately $80 \%$ of indications for DBS are the pharmacologically not efficiently treatable PD and considerably less patients receive DBS for other movement disorders $[3,5]$. The most frequently applied surgical target for PD is the bilateral subthalamic DBS (STN DBS) capable of improving all cardinal symptoms.
Besides the symptomatic improvement, STN DBS can also dramatically and permanently extend the ON time [6, 7] and the health-related quality of life (HRQoL) $[8,9]$.

According to the current guidelines, STN DBS is only indicated in the cases of drug-resistant tremor or severe motor fluctuations unmanageable by pharmacological treatment. The average disease duration at the time of surgery is around 15 years [5], by when the health-related quality of life (HRQoL) and sociocultural functioning are usually impaired [10]. In general, the longer disease duration is associated with the more likely appearance of levodoparesistant symptoms and therefore DBS-resistant symptoms and higher impact on the working capability. One of the 
most important parts of patient selection therefore is the appropriate timing of surgery $[1,11]$. If the DBS implantation is preformed "too late," the presence and severity of DBSresistant symptoms (e.g., postural instability, neurocognitive impairment, or speech problems) might interfere with or worsen the outcome. On the contrary, if the surgery is performed "too early," we might operate on those patients who could have been otherwise well treated pharmacologically and needlessly expose them to the potential surgical risks. Moreover, with "too early" operations we might also include some nonidiopathic cases because the atypical features might be hidden in the early stages of the disease course.

Based on the hypothesis [12-14] that the STN DBS treatment applied at earlier stages of the disease may be superior to the best medication, a multicenter study, called EarlyStim, was initiated [15]. In this prospective study, patients receiving STN DBS had significantly larger improvement in HRQoL (-7.8 improvement on PDQ-38) than patients on best medical treatment $(+0.2$ points worsening, $p=0.002)$ [15]. Although the contributors of EarlyStim study state that, in well-selected cases where the "early" fluctuations impair the sociocultural functioning and HRQoL, STN DBS might be superior to optimal pharmacological treatment [15-17], there are lots of debates on this issue $[18,19]$.

Inspired by the results of EarlyStim study, our research group tried to evaluate if STN DBS might have an impact on the working status of PD patients. Our a priori hypothesis was that STN DBS could preserve working capability of patients having an active job at the time of DBS implantation.

\section{Materials and Methods}

2.1. Patients. Those patients who were included in the present study underwent bilateral STN DBS implantation at University of Pécs and participated in our prospective DBS registry. All patients signed an informed consent form approved by the Regional Ethical Board of University of Pécs. Patients were eligible for STN DBS surgery (and therefore for participating in our DBS registry) if they had the clinical diagnosis of PD in accordance with the UK Brain Bank criteria [20] and at least 5 years of documented disease duration, were under the age of 75 years, had Parkinsonian motor symptoms or dyskinesia that limited their ability to perform the activities of daily living despite optimal oral pharmacological treatment, had no dementia or major psychiatric illness, and had no contraindication to surgery. Presence of dementia was evaluated by the Hungarian validated version of Mattis Dementia Rating Scale (MDRS) [21]. The scores on MDRS can range from 0 to 144 with lower values indicating more severe dementia. Scores on MDRS $\leq 125$ points [21] and/or fulfillment of Diagnostic and Statistical Manual of Mental Disorders 4th Edition Text Revision criteria for dementia were the exclusion criteria for STN DBS surgery.

Out of the group of patients having at least 2 years of postoperative follow-up, first we identified those patients who had an active job at the time of their STN DBS surgery and whose age was comparable with the inclusion criteria of EarlyStim study (18-60 years) [17]. Having an active job was assessed by direct inquiry. Only regular ( $>1$ day/week), either part-time or full-time, work was defined as active job. Working capability was categorized into the following groups:

(i) Full-time work (regular work, 5 days/week and 8 hours/day).

(ii) Part-time work (regular work, 1-5 days/week, 4-8 hours/day).

(iii) Not working, retired due to the disease.

(iv) Not working, retired not due to the disease.

(v) Never worked.

However, we did not consider those who participated only in housework or performed hobby activities or unpaid and irregular tasks as active workers. Altogether $20 \mathrm{PD}$ patients were identified meeting the above mentioned criteria whom we classified into the group of "active job."

To perform pairwise comparison, we chose another 20 patients out of our registry who did not have an active job at the time of their surgery ("no job" group) by the utilization of a custom-made program. The automatic selection process was made in a way that for each participant in the "active job" group we picked a "partner" who had similar age, disease duration, and fluctuation duration (in the range of \pm 2 years) and the same disease type (tremor-dominant versus rigidakinetic type). These matched patients were considered as the "no job" group. We utilized this automatic pairwise selection process to create a "no job" group with balanced and comparable baseline characteristics to the "active job" group.

2.2. Applied Tests. Changes in the working capability and the health-related quality of life were considered as coprimary endpoints. Our primary aim was to identify what portion of young patients having active job at the time of DBS surgery maintained their active job 2 years postoperatively. On the contrary, we also investigated how many young patients not having an active job at DBS initiation returned to work.

For evaluating HRQoL, the EuroQol Instrument (EQ$5 \mathrm{D})$ was assessed. Because the usage of $\mathrm{EQ}-5 \mathrm{D}$ requires only 2 minutes and it was available in validated Hungarian version [22] at the start of our DBS registry project, we chose this HRQoL scale (and not the PDQ-39). EQ-5D had been previously validated [23-25] and utilized in the evaluation of different therapeutic approaches in $\operatorname{PD}[26,27]$. Moreover, it can also be applied to health-related economical calculations [28]. EQ-5D consists of two major parts: a five-item questionnaire and a visual analogue scale (VAS). The first part of EQ-5D maps five different domains of HRQoL: mobility, self-care, usual activities, pain/discomfort, and anxiety/depression [22]. Based on the responses for the five domains questionnaire, an index value vas calculated (coprimary endpoint). The EQ-5D index can be in the range from -0.52 to +1 , the former representing a state worse than death and the latter representing the best health-related status [22]. For the Hungarian population, a change larger than 0.0705 denotes clinically meaningful difference [29]. The response on VAS can range from 0 to 100, the higher values meaning better HRQoL [22]. 
Changes in major motor and nonmotor symptoms were considered as secondary endpoints of the study. Severity of Parkinson's disease was rated by both Hoehn-Yahr Scale (HYS) and Unified Parkinson's Disease Rating Scale [30]. In agreement with the recommendations of the Movement Disorders Society Task Force [31], the original (and not the modified) HYS was utilized. Therefore, in our study, the stage of 2.5 according to the modified HYS was considered as stage 3 (original HYS). The most important secondary outcome of our study was the UPDRS Part III (Motor Examination), where the score can range between 0 and 108 with higher scores indicating worse function [30]. The secondary outcome measures also included changes in activities in daily living measured by the UPDRS Part II and Schwab and England Scale (SES) [32]. Scores for the UPDRS-II can range from 0 to 52 points with higher scores indicating worse function [30]. The scores for SES can be in the range of 0-100 with higher values indicating better function. For neuropsychiatric outcomes, the MDRS and MontgomeryAsberg Depression Rating Scale (MADRS) were assessed. Scores for MADRS can range from 0 to 60 , with higher values indicating more severe depression.

Each scale was assessed by three times (baseline, 1 week preoperatively, and follow-ups, 12 and 24 months postoperatively). All sessions were videotaped enabling us to reevaluate the HYS and UPDRS Part III with the exception of rigidity by a blinded rater. Amount of antiparkinson medication was calculated in levodopa equivalent dosage (LED) [33].

2.3. Statistics. All statistical measurements were performed by the IBM SPSS software package (IBM Inc., USA, version 22.0.1). The level of statistical significance was set at 0.05 . Because most parameters did not follow the normal distribution, nonparametric tests were utilized and median values with interquartile range (IQR: 25th-75th percentile) were calculated.

Changes within each group (baseline versus follow-ups) were tested by Friedman test (baseline versus 1st year of follow-up versus 2nd year of follow-up). For intergroup analyses (e.g., "active job" group versus "no job" group) Mann-Whitney tests were applied. To evaluate changes in dichotomous variables (e.g., having or not having an active job), McNemar test was used.

To overcome the limitations of multiple comparisons, we also applied a mixed-model two-way ANOVA where the first factor has 2 levels and is independent (2 groups: having an active job and not having a job) and the second factor has 3 levels and is repeated (baseline, 1 year, and 2 years). Because ANOVA can provide the difference between the 2 groups at all endpoints, there is no need for further post hoc analyses. Furthermore, using this design, we can also assess the interactions. Because simulation studies using a variety of nonnormal distributions have shown that the false positive rate is not affected very much by this violation of the normality assumption [34-36], the nonnormal distribution of the data did not preclude using such a statistical design.

\section{Results}

3.1. Study Population. For the final analyses, the data of only 20 pairs were included. Due to the pairwise group selection, the most important baseline PD characteristics were comparable (e.g., age, sex, disease duration, disease type, and HYS, Table 1). Although we could not identify any significant differences, the HY staging favored the "no job" group by having more Stage 2 patients than the "active job" group did.

The dosage of antiparkinson medication, severity of motor symptoms (UPDRS-III), major neuropsychiatric symptoms (MADRS and MDRS), and HRQoL (EQ-5D index and VAS) were also similar at baseline (Table 2).

3.2. Working Capability. At baseline, 18 patients had a fulltime job and two patients had a part-time job in the "active group." Two years postoperatively, 16 patients from the "active job" group (80\%) still had an active job (full-time job: 8 patients; part-time job: 8 patients). The reasons for work discontinuation included the reach of official age limit for pension $(n=1)$ and PD-related problems interfering with working capability (e.g., fatigue and some degree of fluctuation, $n=3$ ).

Despite the comparable baseline characteristics and similar improvements in the motor symptoms and activities of daily living, only a single person (5\%) from the "no job" group returned to the world of active work ( $\mathrm{McNemar}$ test; $p<0.01)$.

3.3. HRQoL. Both groups had similar HRQoL at baseline (EQ-5D index values: 0.477 and 0.429 , median values). These values were below the 25th percentile of Hungarian population norms [22]. (The 25th percentile population norms for the 45-54 and 55-64 years age groups are 0.69 and 0.62, resp.) After bilateral STN DBS implantation, the EQ5D index significantly improved in both groups (Table 2, Friedman tests), which clearly exceeded the threshold of minimal clinically important difference (0.0705) [29]. However, 2 years after the operation, the "active job" group members had significantly better HRQoL than the "no job" patients did (Mann-Whitney test, $p<0.001$, Table 2) and this difference was also clinically meaningful. Therefore, the between-groups comparisons revealed better improvement in the primary outcome (HRQoL) in the "active job" group. The application of mixed-model two-way ANOVA with Bonferroni correction further supported that HRQoL 2 years postoperatively was better in the "active job" group than in the "no job" group.

3.4. Secondary Outcomes. As far as the motor symptoms were concerned (UPDRS-III), both groups had similar baseline characteristics and experienced similar improvement after DBS implantation. Two years after the surgery, the motor severity was still comparable in both groups. Moreover, the changes in activities of daily living (SES and UPDRS-II) and antiparkinson medication were also similar in both groups. The only difference in the secondary outcomes was 


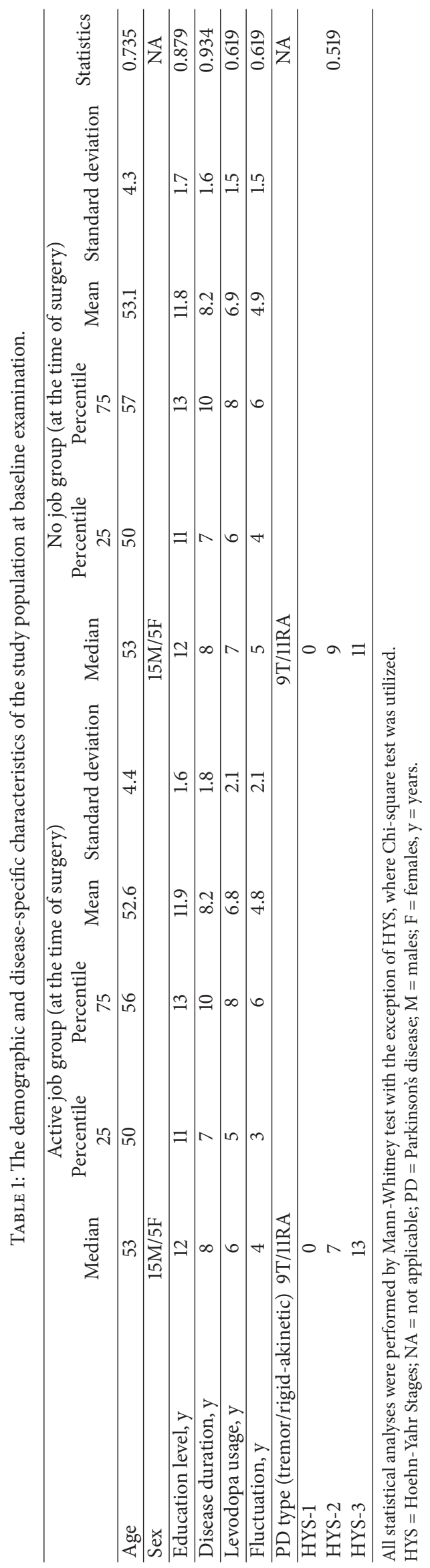




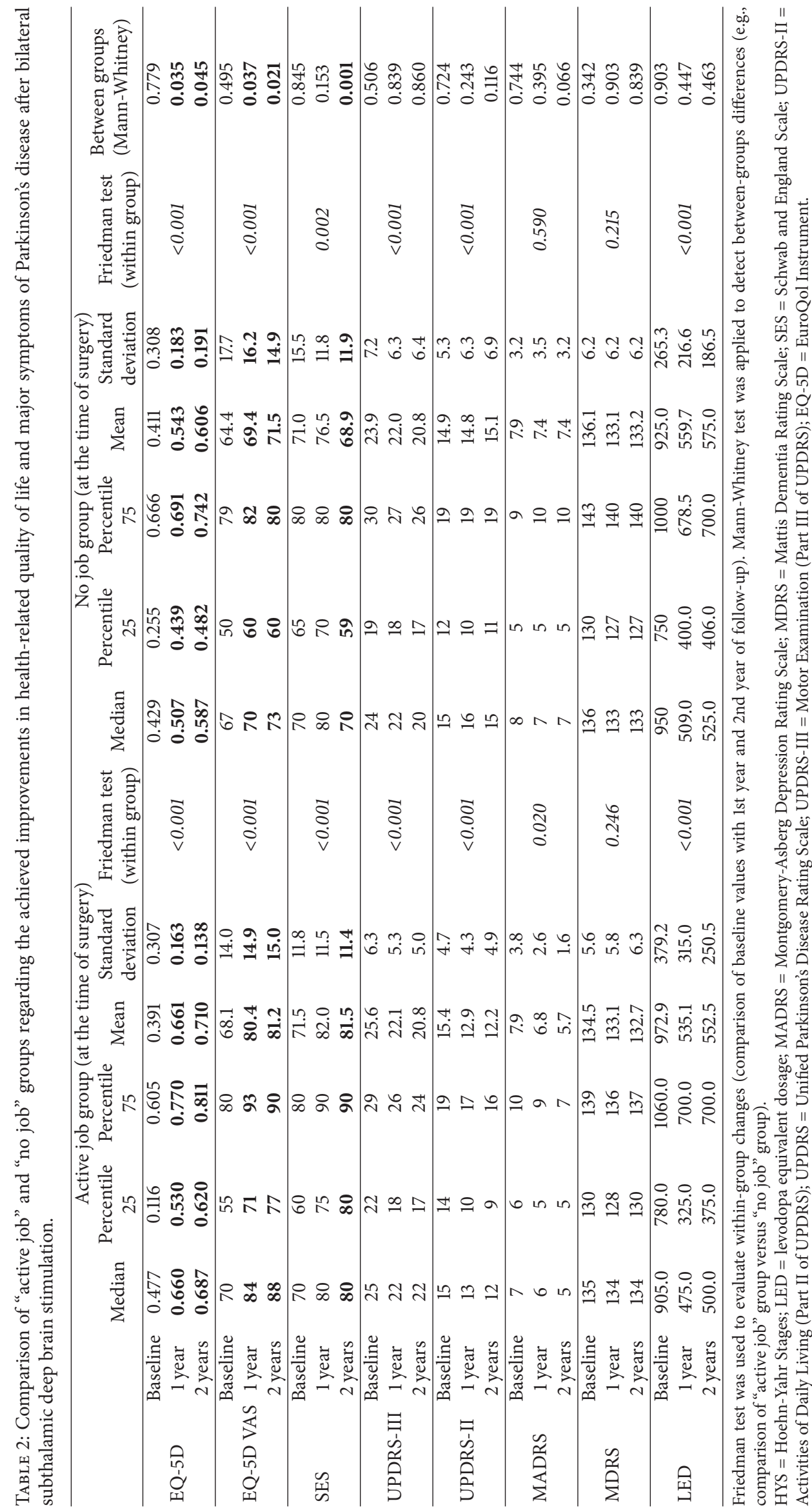


the significant improvement in MADRS score revealed by Friedman test, which was present in the "active job" group but was missing in the "no job" group. The application of mixedmodel two-way ANOVA with Bonferroni correction did not identify any differences in the secondary outcomes.

\section{Discussion}

Our primary aim was to evaluate the hypothesized effect of STN DBS on preserving the working capability of PD patients. In our study, only those patients who were young ( $<60$ years) and had at least 2-year follow-up were included. In the "active job" group, the participants had an active job at the time of surgery but their working capability was impaired by the motor symptoms (both tremor and fluctuations) to some extent. For the "no job" group, we selected patients having similar demographic and PD-related baseline characteristics to perform reliable between-group comparisons.

Our aim was to compare the efficacy of STN DBS on patients having an active job ("active job" group) at the time of surgery to the efficacy of STN DBS on patients without an active job ("no job" group). In case of tremordominant patients, the presence of drug-resistant tremor was the indication for surgery, whereas, in rigid-akinetic patients, the presence of severe fluctuations was the indication for surgery. Because in both groups the number of tremordominant and rigid-akinetic patients was identical due to the pairwise selection, we believe our study design was suitable to draw conclusions.

In the present study, the main focus was to reveal if having an active work at the time of DBS implantation could be a prognostic factor for outcome and this working capability could be preserved by STN DBS. One of the most important findings of our study was that $80 \%$ of patients having an active job at the time of surgery still had an active job 2 years after the DBS implantation. Nevertheless, only a single patient returned to the world of work in the "no job" group after the successful STN DBS therapy. Therefore, we can conclude that DBS might help preserve the working capability if it is performed in patients with active job. On the contrary, if DBS implantation is scheduled after losing the working capability, it might be insufficient to help patients return to work.

The coprimary outcome variable was the change in HRQoL. Patients in the "active job" group experienced higher improvement in HRQoL than patients in the "no job" group did despite the similar changes in motor and major nonmotor symptoms. This finding might suggest that having an active job at the time of DBS surgery might have a beneficial effect on the long-term outcome by being a positive predictive factor.

The only difference in the secondary outcomes was the significant improvement in MADRS score revealed by Friedman test. Because it was not confirmed by the multivariate ANOVA, we considered this difference both clinically and statistically irrelevant.

The authors are aware of the major limitations of their study: not being randomized, placebo-controlled, doubleblind, multicenter, and prospective and having a relatively small sample size. However, our results nicely fit to the concept of EarlyStim because in some individuals the application of "early" DBS might have a beneficial role in the sociocultural functioning. According to our results, in patients with active job, the appropriately "early" usage of STN DBS might help preserve sociocultural functioning and the working capability in a two-year time frame and gain higher improvement in HRQoL. Despite similar symptomatic control, patients receiving STN DBS after losing their working capability seldom return to work again. In the opinion of the authors, having an active job at the time of surgery might be a positive predicting factor for a good outcome. Because the maintenance of working capability is beneficial not only for the patients but also for the healthcare providers, further, larger, controlled trials are warranted to confirm this hypothesis.

\section{Abbreviations}

DBS: Deep brain stimulation

EQ-5D: EuroQol Instrument

HRQoL: Health-related quality of life

HYS: Hoehn-Yahr Stage

LED: Levodopa equivalent dosage

MADRS: Montgomery-Asberg Depression Rating Scale

MDRS: Mattis Dementia Rating Scale

PD: $\quad$ Parkinson's disease

SES: $\quad$ Schwab and England Scale

STN DBS: Bilateral subthalamic deep brain stimulation

UPDRS: Unified Parkinson's Disease Rating Scale

VAS: Visual analogue scale (included in EQ-5D).

\section{Conflict of Interests}

The authors declare that there is no conflict of interests regarding the publication of this paper.

\section{Authors' Contribution}

Norbert Kovács and Sámuel Komoly contributed equally to this work. Sámuel Komoly participated in the conception, organization, and execution of the research project, in review and critique of the statistical analysis, in writing the first draft of the paper, and in review and critique of the paper. Ferenc Nagy participated in the conception and organization of the research project and in review and critique of the paper. Zsuzsanna Aschermann participated in the organization of the research project and in review and critique of the paper. József Janszky participated in the organization of the research project and in review and critique of the paper. Gabriella Deli participated in the organization of the research project and in review and critique of the paper. István Balás participated in the organization of the research project and in review and critique of the paper. Tamás Dóczi participated in the organization of the research project and in review and critique of the paper. Edit Bosnyák participated in the execution of the research project and in review and critique of the paper. Norbert Kovács participated in the conception, organization, 
and execution of the research project, in designing, execution, and review and critique of the statistical analysis, in writing the first draft of the paper, and in review and critique of the paper. Attila Makkos participated in the organization of the research project and in review and critique of the paper.

\section{Acknowledgments}

This study was supported by the Bolyai Scholarship of Hungarian Academy of Sciences, OTKA PD103964, TÁMOP-4.2.2.A-11/1/KONV-2012-0017, and Hungarian Brain Research Program (KTIA_13_NAP-A-II/10) government-based funds. Gabriella Deli reported no financial disclosure. István Balás received $<1000$ EUR consultation fees from Hungarian subsidiaries of Medtronic. Regarding this study, the author did not receive any corporate funding. Sámuel Komoly received $<1000$ EUR consultation fees from Hungarian subsidiaries of Biogen, TEVA, Astellas, Pfizer, and Novartis. Regarding this pilot study, the author did not receive any corporate funding. Tamás Dóczi reported no financial disclosure. József Janszky received $<1000$ EUR consultation fees from Hungarian subsidiaries of UCB, Valeant, and Eisai. Regarding this pilot study, the author did not receive any corporate funding. Zsuzsanna Aschermann received $<1000$ EUR consultation fees from Hungarian subsidiaries of Novartis, GlaxoSmithKline, UCB, and Teva Pharmaceutical Industries Ltd. Regarding this study, the author did not receive any corporate funding. Attila Makkos reported no financial disclosure. Edit Bosnyák reported no financial disclosure. Ferenc Nagy received $<1000$ EUR consultation fees from Hungarian subsidiaries of Boehringer Ingelheim, Novartis, GlaxoSmithKline, UCB, Krka, and AbbVie. Regarding this study, the author did not receive any corporate funding. Norbert Kovács received $<1000$ EUR consultation fees from Hungarian subsidiaries of Medtronic, Boehringer Ingelheim, Novartis, GlaxoSmithKline, UCB, Krka, and AbbVie. Regarding this study, the author did not receive any corporate funding.

\section{References}

[1] N. Kovacs, I. Balas, J. Janszky et al., "Special aspects of patient care after implantation of deep-brain-stimulator," Ideggyógyászati Szemle, vol. 61, pp. 4-15, 2008.

[2] G. Deuschl, C. Schade-Brittinger, P. Krack et al., "A randomized trial of deep-brain stimulation for Parkinson's disease," The New England Journal of Medicine, vol. 355, no. 9, pp. 896-908, 2006.

[3] G. Deli, I. Balás, S. Komoly et al., "Treatment of dystonia by deep brain stimulation: a summary of 40 cases," Ideggyogyaszati Szemle, vol. 65, no. 7-8, pp. 249-260, 2012.

[4] Z. Aschermann, N. Kovacs, and S. Komoly, "Continuous dopaminergic stimulation in Parkinson disease: possibilities in 2013," Ideggyógyászati Szemle, vol. 66, pp. 209-210, 2013.

[5] G. Kleiner-Fisman, J. Herzog, D. N. Fisman et al., "Subthalamic nucleus deep brain stimulation: summary and meta-analysis of outcomes," Movement Disorders, vol. 21, supplement 14, pp. S290-S304, 2006.

[6] G. Fehér, I. Balás, S. Komoly et al., "A kétoldali szubtalamikus stimuláció hatékonysága az antiparkinson gyógyszerelés változtatásának tükrében," Ideggyógyászati Szemle, vol. 63, pp. 314-319, 2010.

[7] G. Tamás, A. Takáts, P. Radics et al., "A mély agyi stimuláció hatékonysága Parkinson-kóros betegeink kezelésébenz," Ideggyógyászati Szemle, vol. 66, pp. 115-120, 2013.

[8] M. C. Rodriguez-Oroz, E. Moro, and P. Krack, "Long-term outcomes of surgical therapies for Parkinson's disease," Movement Disorders, vol. 27, no. 14, pp. 1718-1728, 2012.

[9] A. Fasano, L. M. Romito, A. Daniele et al., "Motor and cognitive outcome in patients with Parkinson's disease 8 years after subthalamic implants," Brain, vol. 133, no. 9, pp. 2664-2676, 2010.

[10] M. Horstink, E. Tolosa, U. Bonuccelli et al., "Review of the therapeutic management of Parkinson's disease. Report of a joint task force of the European Federation of Neurological Societies and the Movement Disorder Society-European Section. Part I: early (uncomplicated) Parkinson's disease," European Journal of Neurology, vol. 13, no. 11, pp. 1170-1185, 2006.

[11] N. Kovács, B. István, L. Carlos et al., "Deep brain stimulation: a breakthrough in the treatment of movement disorders," Lege Artis Medicinae, vol. 19, no. 2, pp. 119-126, 2009.

[12] W. M. M. Schüpbach, D. Maltête, J. L. Houeto et al., "Neurosurgery at an earlier stage of Parkinson disease: a randomized, controlled trial," Neurology, vol. 68, no. 4, pp. 267-271, 2007.

[13] A. E. Lang, J.-L. Houeto, P. Krack et al., "Deep brain stimulation: preoperative issues," Movement Disorders, vol. 21, supplement 14, pp. S171-S196, 2006.

[14] A. E. Lang, "Subthalamic stimulation for Parkinson's diseaseliving better electrically?" The New England Journal of Medicine, vol. 349, no. 20, pp. 1888-1891, 2003.

[15] W. M. M. Schuepbach, J. Rau, K. Knudsen et al., "Neurostimulation for Parkinson's disease with early motor complications," The New England Journal of Medicine, vol. 368, no. 7, pp. 610622, 2013.

[16] W. M. M. Schüpbach, J. Rau, J.-L. Houeto et al., "Myths and facts about the EARLYSTIM study," Movement Disorders, vol. 29, no. 14, pp. 1742-1750, 2014.

[17] G. Deuschl, M. Schüpbach, K. Knudsen et al., "Stimulation of the subthalamic nucleus at an earlier disease stage of Parkinson's disease: concept and standards of the EARLYSTIM-study," Parkinsonism and Related Disorders, vol. 19, no. 1, pp. 56-61, 2013.

[18] T. A. Mestre, A. J. Espay, C. Marras, M. H. Eckman, P. Pollak, and A. E. Lang, "Subthalamic nucleus-deep brain stimulation for early motor complications in Parkinson's diseasethe EARLYSTIM trial: early is not always better," Movement Disorders, vol. 29, no. 14, pp. 1751-1756, 2014.

[19] A. Keitel, S. Ferrea, M. Südmeyer, A. Schnitzler, and L. Wojtecki, "Expectation modulates the effect of deep brain stimulation on motor and cognitive function in tremor-dominant Parkinson's disease," PLoS ONE, vol. 8, no. 12, Article ID e81878, 2013.

[20] I. Litvan, K. P. Bhatia, D. J. Burn et al., "SIC task force appraisal of clinical diagnostic criteria for parkinsonian disorders," Movement Disorders, vol. 18, no. 5, pp. 467-486, 2003.

[21] B. Kaszás, N. Kovács, I. Balás et al., "Sensitivity and specificity of Addenbrooke's Cognitive Examination, Mattis Dementia Rating Scale, Frontal Assessment Battery and Mini Mental State Examination for diagnosing dementia in Parkinson's disease," Parkinsonism and Related Disorders, vol. 18, no. 5, pp. 553-556, 2012. 
[22] A. Szende and R. Németh, "Health-related quality of life of the Hungarian population," Orvosi Hetilap, vol. 144, no. 34, pp. 1667-1674, 2003.

[23] J. Dams, J. Klotsche, B. Bornschein et al., "Mapping the EQ5D index by UPDRS and PDQ-8 in patients with Parkinson's disease," Health and Quality of Life Outcomes, vol. 11, article 35, 2013.

[24] N. Luo, W.-Y. Ng, P.-N. Lau, W.-L. Au, and L. C. S. Tan, "Responsiveness of the EQ-5D and 8-item Parkinson's disease questionnaire (PDQ-8) in a 4-year follow-up study," Quality of Life Research, vol. 19, no. 4, pp. 565-569, 2010.

[25] A. Schrag, C. Selai, M. Jahanshahi, and N. P. Quinn, "The EQ$5 \mathrm{D}-\mathrm{a}$ generic quality of life measure-is a useful instrument to measure quality of life in patients with Parkinson's disease," Journal of Neurology Neurosurgery and Psychiatry, vol. 69, no. 1, pp. 67-73, 2000.

[26] M. Bokor and A. Szentesi, "The effect of Stalevo-dosing on quality of life of Parkinsonian patients with wearing-off," Ideggyogyaszati Szemle, vol. 63, no. 7-8, pp. 247-251, 2010.

[27] P. Klivényi and L. Vécsei, “The use of Stalevo in Hungary for patients with Parkinson disease and its effect on the quality of life," Ideggyógyászati Szemle, vol. 61, no. 1-2, pp. 42-48, 2008.

[28] J. Dams, U. Siebert, B. Bornschein et al., "Cost-effectiveness of deep brain stimulation in patients with Parkinson's disease," Movement Disorders, vol. 28, no. 6, pp. 763-771, 2013.

[29] N. Kovács, Z. Aschermann, P. Ács et al., "The impact of levodopa-carbidopa intestinal gel on health-related quality of life in Parkinson's disease," Ideggyogyaszati Szemle, vol. 67, no. 7-8, pp. 245-250, 2014.

[30] S. Fahn and R. Elton, "Unified Parkinson's disease rating scale," in Recent Developments in Parkinson's Disease, S. Fahn, C. Marsden, M. Goldstein, and D. Calne, Eds., pp. 153-163, 293304, Macmillan Healthcare Information, Florham Park, NJ, USA, 1987.

[31] C. G. Goetz, W. Poewe, O. Rascol et al., "Movement disorder society task force report on the hoehn and yahr staging scale: status and recommendations," Movement Disorders, vol. 19, no. 9, pp. 1020-1028, 2004.

[32] J. Schwab and A. England, "Projection technique for evaluating surgery in Parkinson's disease," in Proceedings of the 3rd Symposium on Parkinson's Disease, F. Gillingham and M. Donaldson, Eds., pp. 152-157, E \& S Livingston, Edinburgh, Scotland, 1969.

[33] C. L. Tomlinson, R. Stowe, S. Patel, C. Rick, R. Gray, and C. E. Clarke, "Systematic review of levodopa dose equivalency reporting in Parkinson's disease," Movement Disorders, vol. 25, no. 15, pp. 2649-2653, 2010.

[34] G. V. Glass, P. D. Peckham, and J. R. Sanders, "Consequences of failure to meet assumptions underlying fixed effects analyses of variance and covariance," Review of Educational Research, vol. 42, no. 3, pp. 237-288, 1972.

[35] M. R. Harwell, E. N. Rubinstein, W. S. Hayes, and C. C. Olds, "Summarizing Monte Carlo results in methodological research: the one- and two-factor fixed effects ANOVA cases," Journal of Educational Statistics, vol. 17, no. 4, pp. 315-339, 1992.

[36] L. M. Lix, J. C. Keselman, and H. J. Keselman, "Consequences of assumption violations revisited: a quantitative review of alternatives to the one-way analysis of variance F test," Review of Educational Research, vol. 66, no. 4, pp. 579-619, 1996. 


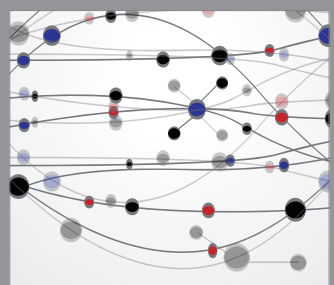

The Scientific World Journal
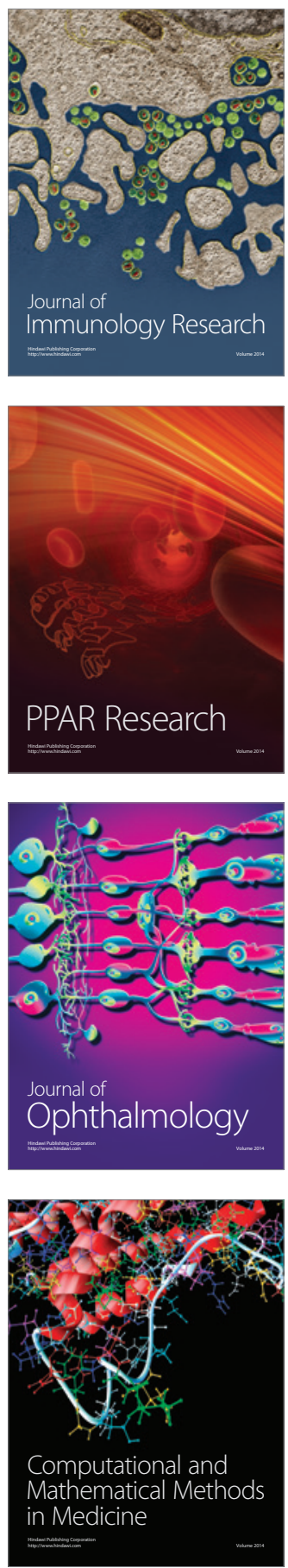

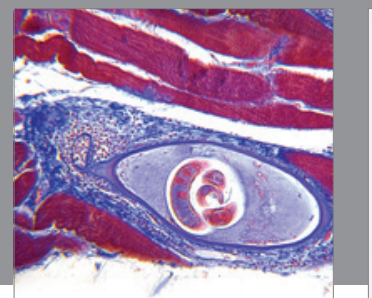

Gastroenterology

Research and Practice
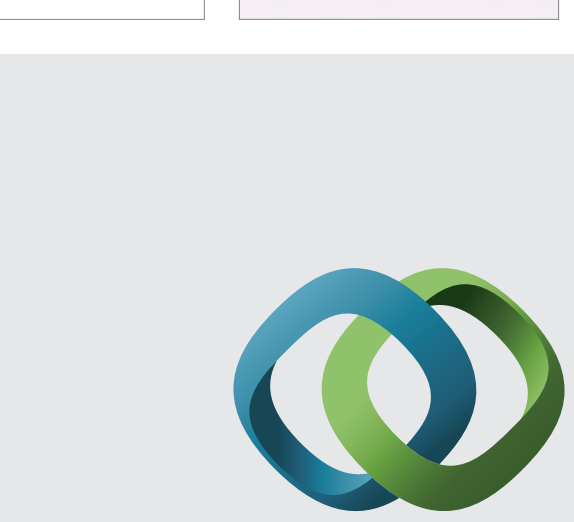

\section{Hindawi}

Submit your manuscripts at

http://www.hindawi.com
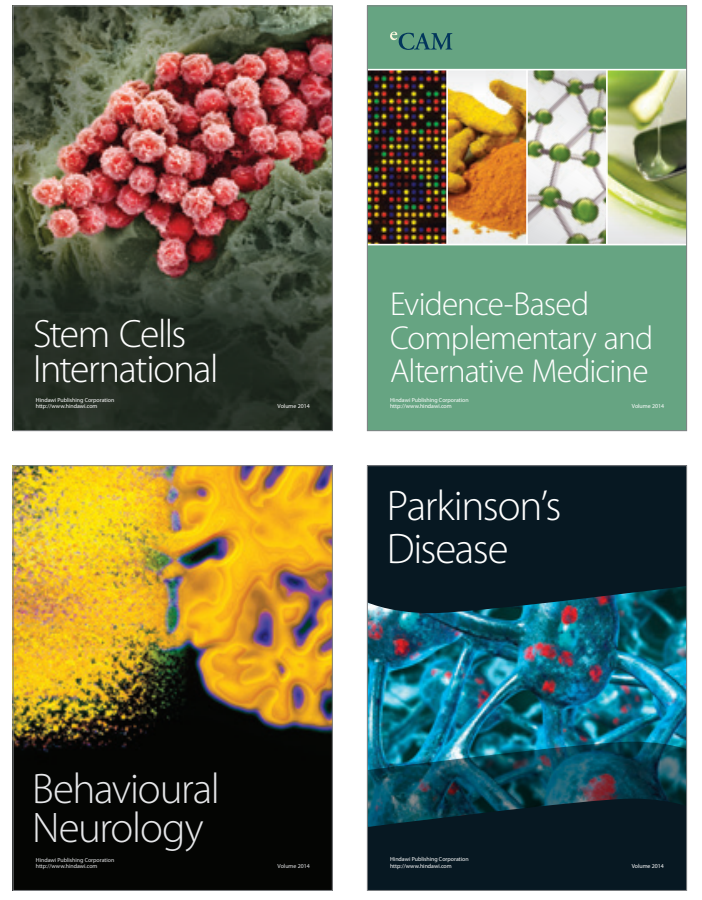
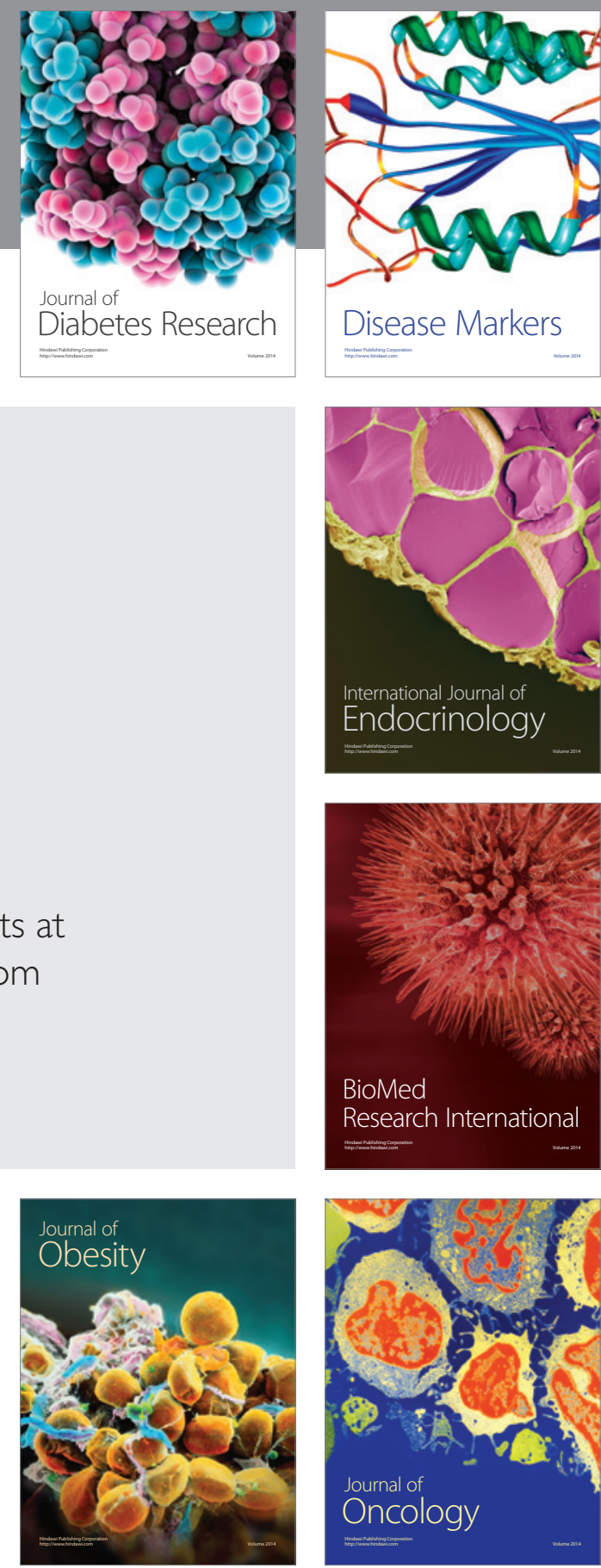

Disease Markers
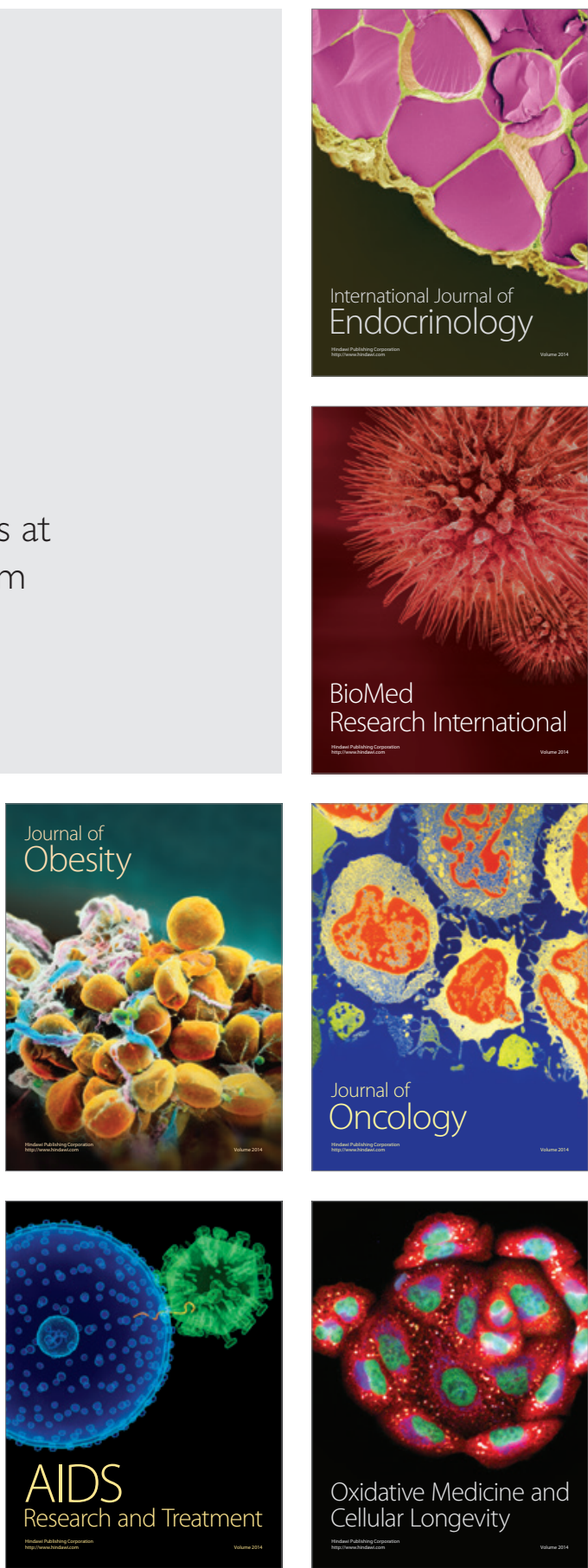